\title{
Maja Lagerqvist
}

\section{Ungdomars resandevärld. Hur kollektivtrafiken tynger och avlastar vardagslivet}

\author{
ur boken \\ Malin Henriksson \& Christina Lindkvist (red.) \\ Kollektiva resor. Utmaningar för socialt hållbar tillgänglighet
}

\author{
Arkiv förlag 2020 \\ Pandoraserien XXVIII
}

FÖRSLAG PÅ KÄLLANGIVELSE:

Lagerqvist, Maja (2020) "Ungdomars resandevärld. Hur kollektivtrafiken tynger och avlastar vardagslivet", i Malin Henriksson \& Christina Lindkvist (red.), Kollektiva resor.

Utmaningar för socialt hållbar tillgänglighet, s. 4I-55, Lund: Arkiv förlag, https://doi.org/IO.I3068/9789179243517.

Det här kapitlet ur en e-bok från Arkiv förlag distribueras fritt över internet genom open access. Titeln finns också tillgänglig $\mathrm{i}$ tryckt utgåva med ISBN: 978 9I 7924350 o.

Verket är upphovsskyddat enligt en upphovsrättslicens från Creative Commons: Erkännande-Ickekommersiell-IngaBearbetningar, som medger ickekommersiell användning och spridning i oförändrat skick så länge källan anges.

Arkiv förlag · Box I559 · 22I OI Lund · BEsöK L Gråbrödersg 3 c, ipg 046-I3 39 20·arkiv@arkiv.nu·www.arkiv.nu

(C) Författarna/Arkiv förlag 2020

E-boksutgåva (PDF) 2020

Beständig länk till hela boken: https://doi.org/IO.I3068/9789179243517

ISBN: 978 9I $792435 \mathrm{I} 7$

ISSN: I4O4-OOOX 



\section{Ungdomars resandevärld. Hur kollektivtrafiken tynger och avlastar vardagslivet}

MAJA LAGERQVIST

Eh, ibland. Alltså, det är såhär, det har hänt att några [killar] har tafsat. Och sen dess har jag känt att det är obehagligt att åka tunnelbana. Jag känner jag vågar inte. (Tjej I6 år, Rågsved)

Om jag är lite trött så tar jag bussen. Men om jag bara vill få allting överstökat snabbt men inte är trött utan har energi då kan jag ta pendeltåget. [...] efter träningen, då är jag ganska trött. Då vill jag bara sitta ner och bara vila. Så efter träningen är bussen skön. (Kille 17 år, Jordbro)

Citaten ovan ger exempel på hur resor med kollektivtrafik både kan underlätta och försvåra vardagslivet. Vi ser hur upplevelser av exempelvis rädsla och lugn ombord bussar och tunnelbanevagnar präglar hur personer mår och reser i vardagen. Vardagslivet innefattar mycket resande. För att kunna ta del av samhället reser vi. Vi reser för att jobba, plugga, roa oss och mötas. Men att resa innebär i sig att vara i samhället. Vi jobbar, pluggar, roar oss och möts, medan vi reser. Vissa grupper i samhället är mer beroende av just kollektivtrafik för sitt resande. Det här kapitlet fokuserar på ungdomar. Det är en grupp som reser mer kollektivt än andra grupper (Trafikförvaltningen 20I6). Det är till och med så att ungdomar som grupp till stora delar är beroende av just kollektiva resor för mycket av sitt vardagliga resande och för att kunna delta i samhället (Barker et al. 2009). Ungdomar är därför extra sårbara om kollektivtrafiken inte fungerar eller ger en obehaglig och otrygg reseupplevelse.

I det här kapitlet undersöker jag hur ungdomar i åldrarna I6 till I9 upplever och förhåller sig till kollektivtrafiken i Stockholm. Jag fokuserar på ungdomarnas reseupplevelser och hur kollektivtrafikens platser (som bussar, tunnelbanor och pendeltåg) kan fungera tyngande och avlastande $\mathrm{i}$ vardagslivet (Friberg et al. 2004). Jag utforskar hur, när och för vem dessa 
offentliga platser erbjuder eller motverkar återhämtning och social interaktion, som är två centrala behov för ungdomars utveckling (Clark och Uzzell 2006). Vi kommer att se hur resandet ger upphov till såväl välmående, interaktion och vila som obehag, rädsla och exkludering, samt hur dessa upplevelser också påverkar individers agerande. I kapitlet uppmärksammar jag hur kollektivtrafiken påverkar människor på olika sätt och de variationer som finns kring praktiker och upplevelser i ungas resande, särskilt utifrån kön.

\section{Ungas resande i forskningen}

Under de senaste decennierna har vikten av att undersöka och ge betydelse till ungas resande och perspektiv lyfts alltmer av såväl myndigheter som inom forskningen om mobilitet och kollektivtrafik (Barker et al. 2009; Carlestam et al. 2012). Men även om betydelsen av ungdomars perspektiv alltmer betonats har forskningen framför allt fokuserat på ungas rörelsemönster och ofta utifrån kvantitativa data. Internationella studier har visat på ungas begränsningar i rörlighet och transport och de variationer som finns utifrån boendeort, klass och kön (t.ex. McCray och Mora 20II; Jones et al. 2000). Överhuvudtaget uppmärksammas ofta att unga är en grupp i samhället som till stora delar är beroende av föräldrars resurser och en väl fungerande kollektivtrafik för sitt vardagliga resande och deltagande i samhället, från skola till sociala aktiviteter. Mindre fokus har lagts vid ungdomars reseupplevelser eller djupare analyser av vad deras resmönster beror på. Vi vet dock att ungas upplevelser av otrygghet och risk begränsar deras resande (Currie et al. 20I3; Ocejo och Tonnelat 20I4). Få studier har undersökt ungdomars mer positiva upplevelser kring kollektivtrafiken, även om betydelsen av ungas resande för socialiserande, självständighet och identitet synliggjorts alltmer på senare tid (Symes 2007; Skelton 2013). Dock präglas tidigare litteratur av att antingen lyfta det begränsande eller det möjliggörande, snarare än ge en sammanvävd bild. I det här kapitlet strävar jag efter att ge en sådan mer sammanvävd förståelse av kollektivtrafikens platser. Jag vill bidra till kunskapsfälten om kollektivtrafik och ungas resande såväl som ungas upplevelser och användning av offentliga platser. Jag gör det genom att lyfta innebörden av kollektivtrafiken som en offentlig plats för unga där det som tynger respektive avlastar ges utrymme. Min studie bidrar med kunskaper om hur kollektivtrafik påverkar ungas resande och varande i vardagen, och hur detta kan variera beroende på social, rumslig och 
tidsmässig kontext. Den ger kunskaper som är väsentliga för att kunna skapa en kollektivtrafik som fungerar för hela samhället. Forskningsfältet kring ungas reseupplevelser domineras av studier från USA, England och Australien. Kapitlet bidrar därför även till kunskapsfältet genom att lyfta ungdomars upplevelser av kollektivtrafik i ett svenskt sammanhang. Jag ska nu gå igenom kapitlets teoretiska infallsvinklar där resandets platser och hur de upplevs står i centrum.

\section{Resandets platser}

Att resa handlar i stort om att ta sig mellan platser. Men resandet i sig möjliggör också skapandet av meningsfulla, rörliga platser, vilka jag benämner "resandets platser". Här inspireras jag av hur mobilitetsforskningen de senaste åren försökt komma vidare från att se resandet i sig som ett vakuum, och istället söka förstå det utifrån kroppsliga och sociala upplevelser (Sheller och Urry 2006). Alltså kan bussen, tåget eller tunnelbanan begripliggöras som en plats; en plats som formar och formas av människors upplevelser och handlande, istället för att vara ett neutralt medel för att nå ett mål (Jiron 2009). Forskningen om mobilitet har på senare tid blivit alltmer intresserad av rörlighetens materiella och fasta dimensioner och av relationerna mellan mobilitet och stillhet; hur de är olika sidor av samma mynt och influerar varandra. Resandets platser, som bussar och tunnelbanevagnar, innebär såväl rörelse (till olika destinationer) som stillhet (att behöva vara kvar i tunnelbanevagnen tills man nått sin destination). Precis som andra platser är de - om vi utgår från hur geografen Doreen Massey (2005) beskriver platser - alltid föränderliga, kontextuella och står i relation till dem som använder dem och till andra platser. Resandets platser är vardagliga platser med egenskaper och variationer utifrån användare, fysiska former, sociala relationer samt tidsmässiga och geografiska kontexter. De förflyttar sig genom det geografiska rummet under olika tider och med skiftande användare. Nästa avsnitt kopplar samman dessa platser med just resenärsgruppen ungdomar.

\section{Ungdomars behov av olika platser}

Urbansociologen Mats Lieberg har i studier av ungdomars användning av sin omgivning betonat två typer av viktiga platser: platser för interaktion och platser för tillflykt. Medan den första är platser där man kan se andra och visa sig själv, är den senare platser att dra sig tillbaka på när 
man är trött på att visa upp sig (Lieberg 1995). Överhuvudtaget har forskning om ungdomar uppmärksammat betydelsen av att ha en plats att dra sig tillbaka på, där de kan återhämta sig, hantera stress, organisera sina egna tankar och känslor och komma undan vardagslivets begränsningar, kontroll och fragmentering. Social interaktion och tillflykt är två centrala behov för ungdomar, då de är i en period av stark utveckling mot självständighet och vuxenliv (Clark och Uzzell 2006), även om liknande behov finns i alla åldrar. Resandets platsers möjliga roll för dessa behov blir extra intressant i och med att ungdomar rent generellt är mer ofria på såväl offentliga som privata platser i jämförelse med vuxna. De har i än lägre grad än vuxna kontroll och äganderätt över platser i sin vardag, som i hemmet. Deras närvaro och umgänge är ofta bevakade, och ifrågasatta, av vuxenvärlden i miljöer som köpcentrum och parker (Childress 2004). Buss och tunnelbana skulle vid sidan av att de utgör viktiga transportmedel också kunna vara platser där ungdomar faktiskt kan vara ensamma, eller tillsammans med andra, utan övervakande föräldrar eller skolpersonal.

\section{Avlastning och tyngd}

För att analysera ungdomarnas upplevelser av resandets platser använder jag begreppen "tyngd" och "avlastning", inspirerad av Friberg med kollegor (2004). I en genusanalys av resande använder de begreppen för att förklara att olika situationer eller företeelser upplevs som att de avlastar vardagslivet eller ger det en ökad tyngd: "Tyngden är upplevelsen av att de materiella strukturerna tynger och begränsar, medan avlastning är det materiellas bidrag till känslan av frihet" (Friberg et al. 2004, s. 27). Med materiella strukturer avses bebyggelse och annan infrastruktur, och här kan kollektivtrafik inräknas, men även sociala och emotionella aspekter tas in i Friberg med fleras analys. På liknande sätt inkluderar min analys såväl materiella som sociala och emotionella sammanhang vilka kan kopplas till resandet i kollektivtrafiken. Begreppen "tyngd" och "avlastning" används alltså här för att analysera ungdomarnas reseupplevelser utifrån upplevda möjligheter och begränsningar i resandet och dess platser. Vidare, för att förstå hur tyngande och avlastande upplevelser av kollektivtrafiken kan prägla hur ungdomar använder, uppfattar och reflekterar kring kollektivtrafiken är begreppet "mobilitetsstrategier" användbart. Sociologen Sven Kesselring (2006) använder begreppet för att visa hur och varför individer rör sig och navigerar genom de platser de 
lever i. Han påpekar att dessa strategier formas av kontextuella situationer, ekonomiska och sociala förhållanden och maktrelationer, men även av individers egna beslut och förmågor att påverka och anpassa hur de rör sig på platser.

\section{Samtal med ungdomar}

I kapitlet analyserar jag 47 intervjuer med ungdomar. Intervjuerna genomfördes under 2016 och 2017 i fyra gymnasieskolor i Stockholms län. Ungdomarna i studien var I6 till I9 år gamla. Genom att göra intervjuerna i fyra olika gymnasieskolor inkluderar undersökningen ungdomar boende i olika bostadsområden och delar av Stockholm. Två av skolorna innebar intervjuer med unga som i huvudsak bor i bostadsområden som ligger relativt långt ut i Stockholms södra förorter och som till stor del kan klassas som socioekonomiskt utsatta med en relativt hög andel låginkomsttagare. De två andra skolorna innebar intervjuer med unga som framför allt bor i välbärgade bostadsområden, i innerstaden såväl som i förorter söder, sydöst och nordväst om centrala Stockholm. Urvalet av skolor och respondenter baseras på en önskan om en jämn könsfördelning och att inkludera ungdomar boende i en rad olika bostadsområden gällande socioekonomi, belägenhet i Stockholm och typ av kollektivtrafik (som buss, pendeltåg och tunnelbana). På så vis kan en relativt bred förståelse av hur ungdomar i Stockholm upplever kollektivtrafiken möjliggöras. Ungdomar är inte en homogen grupp i samhället. Det finns dock vissa gemensamma drag hos de som intervjuats i den här studien, nämligen att de alla fortfarande går i skolan, bor hos någon förälder $\mathrm{i}$ Stockholm och använder samma kollektivtrafiksystem.

Intervjuerna genomfördes efter kontakt med lärare. Jag fick chansen att träffa flera klasser och intervjua stora delar av klasserna under skoltid. Intervjuerna var individuella och frivilliga, anonymitet garanterades och ungdomarna fick möjligheten att avbryta när de ville, vilket ingen gjorde. Många ville delta och uppskattade att bli lyssnade på, även om de till en början kunde vara ganska korta i sina svar och flera följdfrågor behövdes för att få ungdomarna att berätta om sina upplevelser av kollektivtrafiken. De semistrukturerade intervjuerna fokuserade på hur respondenterna rörde sig i vardagen och deras upplevelser av olika sätt att resa. Intervjuerna transkriberades och har analyserats tematiskt med hjälp av begreppen tyngd och avlastning och idén om resandets platser som möjliga platser för social interaktion och för tillflykt. Analysen och 
kunskapsproduktionen är baserad på hur respondenterna själva beskriver och tolkar sina erfarenheter. Detta är ett sätt att ge röst till individer inom en åldersgrupp som ofta blir dold mellan vad som ses som barn och som vuxna (Skelton 2013). Könsfördelningen bland respondenterna var relativt jämn och de hade olika etniska bakgrunder. Av de 47 ungdomarna är 9 utlandsfödda och 38 är födda i Sverige. 24 av ungdomarna har minst en förälder som är född utomlands. I analysen av materialet framstod skillnader mellan tjejer och killar samt mellan upplevelsen av buss och tunnelbana som mer framträdande än etnisk bakgrund och socioekonomiska skillnader. Det är därför framför allt dessa dimensioner av studien som kommer att presenteras och diskuteras nedan.

\section{Ungas upplevelser av resandets platser i Stockholm}

I de kommande avsnitten behandlar jag upplevelser av hur, när och varför kollektivtrafiken ger tyngd eller avlastning. En tydlig avlastning är när bussar och tunnelbanor tar personer dit de behöver, men här kommer andra aspekter synliggöras. Olika känslor och kroppsliga upplevelser, och hur dessa kan skilja sig mellan exempelvis olika trafikslag och mellan tjejer och killar, kommer att bli tydliga.

\section{Avlastning i vardagen}

Jag tycker om bussen för att jag gillar att bara sitta en stund. Och det är bara lugnt. [...] efter skolan så är jag trött, så jag gillar att sitta kvar typ en kvart. Och bara vila. (Tjej 17 år, Jordbro)

Ungdomarna synliggör kollektivtrafikens avlastande karaktär tydligt i beskrivningarna av upplevelsen av att åka buss. Avlastningen handlar om att bussen som plats erbjuder ett lugn, som vi kan se i citatet ovan och $\mathrm{i}$ inledningen. Det är en plats som ofta beskrivs som mindre präglad av stress i jämförelse med tunnelbanan. Många berättar att de särskilt föredrar bussen när de är trötta. Bussen blir också avlastande för att, eller när, den ger möjlighet till ett mindre upphackat resande. Flera av ungdomarna använder sig av strategin att välja en tidsmässigt längre bussresa för att få resan samlad till en och samma plats, eller i varje fall skapa en resa med färre byten.

Vidare upplever många att bussen ger ett lugn för att det är färre människor där, även om detta såklart beror på tid på dygnet. Respondenterna menar att bussen erbjuder en miljö som känns mer småskalig, 
skyddad och mysig. Den småskaliga miljön gör det enklare att ha översikt över de andra som reser. Detta ger en känsla av trygghet, vilket också förstärks av möjligheten att ha kontakt med en chaufför:

Jag känner mig typ trygg i bussen. Det är smalt, eller typ trångt och så finns det bara två sittplatser och man kan liksom se allt. För i tunnelbanan är det liksom svårt att se, det är bredare och mycket människor. Så buss är skönt. (Tjej 17 år, Brandbergen)

Jag gillar ju mest att åka buss. Fast det är inte alls smidigast. Då måste man ta hänsyn till köer och ... ja det går ju snabbast med tunnelbanan. Bussen är bekvämast om man sitter mer ensam typ, och lite mysigare. (Tjej I8 år, Vallentuna)

Buss är det trafikslag som ungdomarna alltså tydligast skildrar som en avlastande plats. Det är även det färdsättet som flest tycker om. Över hälften av de intervjuade föredrar bussen, och framför allt tjejerna. Bland dem finns både de som bor i områden som endast trafikeras av busstrafik och de som bor i områden som har tunnelbane- eller pendeltågstrafik, både ungdomar som bor centralt och långt bort, och både de som bor $\mathrm{i}$ socioekonomiskt utsatta områden och i mer välbärgade områden.

Tunnelbanan lyfts å andra sidan som avlastande utifrån dess snabbhet, bekvämhet och pålitlighet. Det är dock framför allt killar som säger att de föredrar tunnelbanan. Men i såväl tjejers som killars berättelser konstrueras tunnelbanan som en plats där du som resenär tydligt blir en del av ett större sammankopplat system som gör att många platser lätt kan nås:

I en buss så kan du sitta fast i trafiken i flera timmar. Med tunnelbana, det är sällan man hör att det är problem med dem. De rullar på hela tiden. Och går mycket snabbare. Det känns som mer harmoniskt att åka tunnelbana. (Kille I8 år, Hallunda)

Tunnelbana är ju väldigt effektivt och det är ju skönt. Alltså om jag är inne i stan tar jag hellre tunnelbana än buss. Men jag tycker att själva miljön på bussarna är mysigare än tunnelbanan. (Tjej 17 år, Saltsjö-Boo)

Här kan vi se att buss och tunnelbana ofta upplevs och beskrivs som två olika typer av platser. Deras avlastande och tyngande egenskaper är något som ofta förklaras genom att de kontrasteras med varandra, även om det kan vara olika aspekter med buss respektive tunnelbana som upplevs som avlastande eller tyngande. 


\title{
Tyngder i vardagen
}

Det som avlastar vissa kan dock av andra upplevas som tyngande. Den upplevda småskalighet som uppskattas hos bussen uppfattas av några av ungdomarna som jobbig och begränsande. Det gör att det blir trångt, instängt och dålig luft. En del uppfattar också bussen som långsam. Den tar mycket tid i anspråk, fastnar i trafik och är försenad:

\begin{abstract}
Det är snabbast med tunnelbanan. Bussen, den åker igenom massa byggnader och gator som man inte behöver. Tunnelbanan går till centrum direkt. Därför är det bättre. Smidigare. (Kille I7 år, Vårby gård)

Jag fördrar att gå men om man ska välja något sätt att åka så tycker jag tunnelbanan. För att den går ofta och man vet att oavsett när man kommer till tunnelbanan, så vet man att det är mindre än tio minuter, var man än ska åka. Det är skönt att man slipper tänka på att man måste tajma, som bussar eller något som går mer sällan. Och så vet jag var tunnelbanan går. Bussarna de kan ju gå lite hur som helst. Och de har ju ingen begränsning, tunnelbanan kan ju inte råka svänga in på fel station, så att säga. (Kille $\mathrm{I} 8$ år, Vasastan)
\end{abstract}

Bussen tycks här alltså kunna ge en känsla av begränsad rörelsefrihet. Vidare förmedlar ungdomarna att de upplever tydliga kroppsliga begränsningar och obehag i både tunnelbana och buss. Resandets platser kan vara smutsiga och varma. Det kan också finnas människor där som luktar illa eller står för nära. Det kan vara trångt och svårt att andas och röra sig som man vill. Förseningar tynger också vardagen vilket tydligt förmedlas av ungdomarna, framför allt angående busstrafiken:

Den kommer ofta för sent. Eller den kommer alltid för sent. Det är konstigt när den kommer i tid. Och ibland så kommer inte bussen alls. (Tjej I7, Hässelby villastad)

Förseningarna påverkar upplevelserna av resandet och skapar friktion och irritation. Flera beskriver svårigheter att ta sig till skolan i tid och att planera resten av livet. Trots bussens förseningar är det tunnelbanan som respondenterna ändå tydligast lyfter som en negativ plats. Flera av respondenterna försöker undvika den så långt som möjligt. En del i de tyngande upplevelserna är att det är mycket folk på och kring tunnelbanan, vilket innebär att det blir extra trångt, stressigt och smutsigt:

Ibland är det fullt. Ibland luktar det illa. Ibland är stolarna smutsiga för att någon har haft sina fötter på. Man mår inte bra. (Kille I7 år, Vårby gård) 
Respondenterna beskriver också tunnelbanan som stökig och obehaglig utifrån hur de som reser med den beter sig. Det gäller framför allt på kvällar och helger:

Tunnelbanan blir för mycket ljud. Alla skriker så mycket. Speciellt om man åker på natten, då skriker alla. De är fulla och man ser mycket saker. (Tjej 17 år, Alby)

Tunnelbanans avlastning genom sin pålitlighet gäller alltså inte tunnelbanan som social plats. En allvarlig tyngd som framkommer i intervjuerna kan kopplas till sexuella och rasistiska trakasserier, där alkohol också kan vara inblandat. Dessa tyngande händelser sker framför allt i tunnelbanan, och det är framför allt, om än inte bara, tjejer som uttrycker denna tyngd starkast. Flera beskriver upplevelser som tydligt påverkat deras känsla av trygghet, integritet och vilja att resa under specifika tider eller med specifika trafikslag. I och med dessa upplevelser blir resandet en tyngd i vardagslivet, en inskränkning i rörelsefriheten:

Det är väl såhär lite äldre killar som är fulla och ska hålla på och typ du vet, alltså. Men det är ju inte tunnelbanans fel. Men i min position så är det lite obehagligt.

Och jag tror också att det är många som känner så. (Tjej I7 år, Saltsjö-Boo)

Citatet synliggör ett obehag som flera av de unga tjejerna i studien beskriver angående upplevelser av män i kollektivtrafiken. Vi ser här hur genusförhållanden genomsyrar upplevelserna av tyngd, vilket också är något som Friberg med kollegor (2004) tydligt lyft tidigare. Jag återkommer till det och till denna typ av besvärliga sociala interaktioner.

\section{Platser för tillflykt}

Det är skönt att bara sitta där [på bussen] och bara gunga. Det är mycket mindre stressigt än på tunnelbanan. Sitta lite mer själv. Jag tycker om att sitta och titta ut genom fönstret. (Tjej I8 år, Hanviken)

Som en utveckling av resonemanget om resandets platsers avlastande egenskaper kan man se att framför allt bussen, mer än tunnelbanan, framstår som en egen avskild plats för ungdomarna. En plats för det som Lieberg (1995) betecknar som "tillflykt". Det är en plats att tänka och läsa på, eller bara betrakta världen från. Det är en plats att dra sig undan på, där du kan vara själv och använda mobilen, utan att någon säger till eller kontrollerar vad du gör. Dessa avlastande och möjliggörande aspekter av bussen sätts ofta i relation till tunnelbanan eller skolan, där ungdomarna upplever att de inte kan slappna av eller bara vara på samma sätt som de kan på bussen. 
Vidare lyssnar nästan alla ungdomar på musik medan de reser med såväl buss som tunnelbana. En I9-årig tjej som bor på Södermalm berättar att hon tycker det är "jättehärligt att sitta på en buss vid en fönsterplats och lyssna på musik”. Telefon och musik beskrivs som ett sätt att stänga ute ljuden från folk och stad runt omkring, som i citatet nedan:

Leka med mobilen, lyssna på musik. Man kopplar bort de olika ljuden runt om också. Folk gapar och skriker. Allt är ju högt. (Kille ı8 år, Hallunda)

Det intensiva mobilanvändandet, kombinerat med hörlurar, kan förstås som ett sätt att behålla integritet och kroppslig autonomi under färden. Samtidigt kan det ge en viss avkoppling från den stundvis stressade och tyngande tillvaro de unga upplever och som resandet i kollektivtrafiken kan medföra.

\section{Platser för önskad, och oönskad, interaktion}

Förutom att vara en plats för tillflykt kan bussen även förstås som en plats för social interaktion. ”Jag sitter och tänker på grejer. Eller så håller jag på med min lur, skriver till mina kompisar" säger en I6-årig kille som bor i Jordbro, medan en I8-årig tjej i Skarpnäck förklarar varför hon åker buss med att säga:

Jag tar bussen till tunnelbanan. Jag behöver inte ta den, det är en station. Men det är för att då kommer de som jag växte upp med, de åker med den bussen. Jag brukar hoppa på bussen och åka med dem.

Det är alltså en plats där man kan umgås, virtuellt eller fysiskt, med vänner. Detsamma gäller för tunnelbanan. Det är en plats för vänner att resa ihop på, likt en förlängd fest eller fika. En I8-årig tjej från Bromma säger: "Och sen tycker jag att det är ganska trevligt att åka tunnelbana om man är ett stort gäng också. Det blir lite kul.” Såväl buss som tunnelbana omtalas alltså som sociala platser där ungdomarna interagerar med vänner och andra de känner, där de hinner med det sociala och upprätthåller kontakter.

Social interaktion under resan kan vara något som eftersträvas och som avlastar vardagen. Det behöver dock inte vara det. I studien blir det påtagligt att ungdomarna aktivt försöker undvika viss interaktion, om det är möjligt. Det framkommer gång på gång i intervjuerna och kan illustreras av ett av citaten i kapitlets inledning och av citatet nedan: 
Det finns ju alltid en sån tanke, om nån kommer tafsa på mig. Det är väl fotbollsmatcher i så fall [som är obehagliga], det tycker jag inte om, alltså efter fotbollsmatcher. Då skulle jag definitivt undvika att åka kommunalt. (Tjej I7 år, Segeltorp)

I intervjumaterialet blir det tydligt att det framför allt är tjejer, och nära på alla tjejer i studien, som beskriver obehagliga eller otrygga vistelser i anslutning till kollektivtrafikens platser. Det är särskilt tunnelbanan som lyfts som exempel. Förutom variationer mellan olika resenärer och färdmedel visar ungdomarnas berättelser hur upplevelsen av buss och tunnelbana varierar utifrån kontext, som var och när resandet sker. En och samma buss kan kännas tryggare ju närmare hemmet den är, utifrån tidpunkt eller förekomst och sammansättning av människor på platsen. En I8-årig tjej i Bromma berättar att hon upplever det som särskilt otäckt att resa med kollektivtrafik i vissa sammanhang:

På kvällen. Och sen är det väl vissa områden som det är mer obehagligt [att åka genom]. Jag känner mig väldigt trygg på lokala bussen. Det är ju så nära hemma. Man träffar nästan alltid på folk man känner. Så det är obehagligare att åka runt själv inne i stan. Det är så långt hemifrån.

Utifrån det som framkommit i kapitlet kan vi se att bussen framställs som ett förlängt vardagsrum eller kanske snarare, utifrån ett ungdomsperspektiv, som en förlängning av det egna sovrummet. Det är en mer sluten och enskild plats som är mindre anonym och där de resande kan få ro. Tunnelbanan å andra sidan framstår som en mer offentlig och öppen plats, med flöden av okända människor och kopplingar till övriga staden.

Resandets platser tycks alltså fungera som möjliggörande och avlastande platser, som kan ge såväl social interaktion som tillflykt. De kan vara platser där ungdomarna får vara på ett relativt ostört och självständigt sätt, både med sig själv och med andra. Men tidvis, bitvis och för vissa mer än andra, är resandets platser också platser kantade med friktioner. Här finns stress, störningar och oro, från såväl ljud, lukter och smuts som från folkflöden, folktomhet och obehagliga eller hotande människor. I intervjuerna framkommer det gång på gång att ungdomarnas upplevelser av resandets platser - det som avlastar och det som tynger - faktiskt påverkar hur de mår och deras resandestrategier. Detta kommer diskuteras mer i kapitlets avslutning. 


\section{Slutsatser}

Intervjumaterialet $\mathrm{i}$ sin helhet visar skillnader mellan killar och tjejer angående vilka trafikslag som helst väljs och hur resandets platser uppfattas. Exempelvis uppskattar tjejerna bussen mer än tunnelbanan, medan tunnelbanans fördelar nästan bara lyfts av killar. Det är påtagligt ofta som tjejerna uttrycker kroppslig utsatthet och upplever andra resenärer som obehagliga, särskilt i förhållande till att åka tunnelbana och särskilt på kvällen. De väljer i mycket större utsträckning att åka buss, även om det tar längre tid just för att det känns tryggare. När killarna pratar om obehag handlar det oftare om upplevelser av trängsel, smuts och lukter. Vi ser här att upplevelserna av tyngd och avlastning på olika platser och i olika situationer inom kollektivtrafiken har en genusdimension. Det blir tydligt att tjejer upplever, och försöker undvika, en viss typ av tyngd som killarna inte upplever (eller i alla fall inte förmedlar i intervjuerna). Friberg med kollegor gör en liknande koppling mellan kön och upplevelser av tyngd och avlastning i sin analys av pendlare. Också i deras analys blir det påtagligt hur mycket känslan av tyngd faktiskt påverkar såväl reseplanering som upplevelser av resandet och då särskilt för kvinnor (Friberg et al. 2004, s. I04).

Forskning och rapporter har sedan många år pekat på kvinnors otrygghet i offentliga miljöer och att unga kvinnor upplever, eller i alla fall uttrycker, större otrygghet än unga män och i högre grad ändrar sitt beteende utifrån det (Brottsförebyggande rådets nationella trygghetsundersökningar, se Söderström et al. 2019; Koskela och Pain 2000; Listerborn 2002; Johansson et al. 20I2). Vad den här studien visar är alltså inte en nyhet. Det är dock viktigt att även fortsatt uppmärksamma att unga kvinnor uttrycker denna typ av erfarenheter och känslor. För upplevd otrygghet har betydelse. Det både begränsar individer och påverkar användningen av det geografiska rummet. När individer upplever otrygghet på en plats påverkar det vilka som i förlängningen vistas där, eftersom människor låter bli (om de kan) att röra sig på platser som de förknippar med personlig risk (Koskela och Pain 2000; Gardner et al. 20I7).

Intervjuerna visar att upplevd tyngd och avlastning, som känslor av otrygghet och obehag eller trygghet och ro, formar hur ungdomarna reser och förhåller sig till detta resande och till resandets platser. Upplevelserna påverkar alltså det som Kesselring (2006) kallar mobilitetsstrategier. Precis som Kesselring lyft, så formas ungdomarnas navigation genom den värld de lever i av kontexter och sociala förhållanden men också av indi- 
viders egna beslut och förmågor att påverka och anpassa hur de rör sig. I intervjuerna uttrycker de tydliga, och varierande, strategier och skäl kring sitt resande, som vad de väljer att resa med och när och hur de ändrar sina sätt att resa. Vi har sett hur specifika behov, som att behöva vila eller möta vänner, upplevelser av otrygghet och tidigare erfarenheter av obehagliga människor, men också situation och kontext, formar valen i resandet. Ungdomarna tar exempelvis inte alltid det snabbaste alternativet utan väljer olika vägar eller färdsätt beroende på hur de mår just där och då, vad de behöver göra efteråt och om de vill undvika stressiga platser, obehag eller utifrån den upplevda tyngd som en fragmenterad resa kan innebära (jfr Friberg et al. 2004). Kunskaper om vad som faktiskt präglar olika människors mobilitetsstrategier är värdefulla. De behövs för att skapa ett brett funktionellt transportsystem som inte bara prioriterar att skapa snabbaste resan mellan A och $\mathrm{B}$, utan också ser till människors olika behov och förutsättningar.

Den här studien har i motsats till tidigare forskning fördjupat sig i ungdomars upplevelser och värdering av kollektivtrafiken. Ett kunskapsbidrag är att den lyfter kollektivtrafikens olika värden och betydelser. Kapitlet visar när och hur det kollektiva resandet förbättrar livet, som i att skapa välmående, interaktion, avkoppling, tillgänglighet, rörelsefrihet och trygghet. Det visar även när och hur kollektivtrafiken innebär tyngd, obehag, barriär och begränsning. Tidigare forskning har ofta fokuserat på det ena eller det andra, som att uppmärksamma kollektivtrafikens betydelse för social interaktion och ungas självständighet (Symes 2007; Skelton 2013) eller hur rädslor begränsar deras vardagsresande (Jones et al. 2000). Det finns emellertid en styrka i att visa mångtydigheten, nyanserna och föränderligheten som dessa platser kan ha. Intervjuer som metod har en möjlighet att fånga just detta. Intervjuer kan synliggöra såväl positiva som negativa sociala konsekvenser av kollektivtrafiken och identifiera hur resandets platser verkligen är mångsidiga. Som att tunnelbanan kan upplevas som både det bästa och det sämsta. Att bussens uppskattade småskalighet också kan vara jobbig. Att människor på dessa platser kan ge både trygghet och obehag. Att upplevelser av begränsningar och friheter kan rymmas, och skifta, inom en och samma plats. Denna komplexitet är viktig att vara medveten om i planering och värdering av transportsystem för att förstå hur, när, var eller för vem kollektivtrafiken kan vara nyttig. Ett första steg i att hantera komplexiteten är att utgå ifrån att kollektivtrafiken består av en mängd olika platser, som medvetet kan utformas och 
förbättras utifrån olika gruppers behov, istället för att se systemet som ett flöde av rörelser. Ett annat steg är att behålla variationerna inom systemet så att det finns olika färdsätt, och platser, att välja på för människors resor. Det är mitt råd till nutidens och framtidens planerare, politiker och andra som vill skapa en mer inkluderande kollektivtrafik.

Att bussen är det färdsätt som ungdomar, och särskilt tjejer, föredrar bör ställas i relation till att det idag dröms om och satsas på framför allt spårbunden kollektivtrafik i arbetet för en hållbar utveckling. I visionerna för framtidens trafik lyfts ofta även förarlösa bussar och tåg (t.ex. Boverket 20I2; Regeringskansliet 20I8). Ur ett trygghetsperspektiv ter sig den typen av satsningar som potentiellt problematiska, särskilt för grupper som unga tjejer som redan upplever en ökande otrygghet i offentliga miljöer (Söderström et al. 20I9). Det är därför viktigt att fundera vidare på vilka platser och villkor som skapas, och vem som blir vinnare och vem som blir förlorare, i framtidens kollektivtrafik.

\section{Litteratur}

Barker, J., Kraftl, P., Horton, J., Tucker, F. 2009. The road less travelled: New directions in children and young people's mobility. Mobilities, 4(I), I-IO.

Boverket 2012. Vision for Sverige 2025, dnr 109-2640/20II: rapportering av regeringsuppdrag. Karlskrona, Boverket.

Carlestam, H., Blid, P., Fernström, P. 2012. Unga om olika trafikslag. Sex fokusgrupper med unga vuxna $i$ åldern I8-24 år. Rapport. Trafikanalys/Novus.

Childress, H. 2004. Teenagers, territory and the appropriation of space. Childhood, II(2), I95-205.

Clark, C., Uzzell, D. 2006. The socio-environmental affordances of adolescents' environments. I Spencer, C., Blades, M. (red.), Children and their environments, s. 176-198. Cambridge, Cambridge University Press.

Currie, G., Delbosc, A., Mahmoud, S. 2013. Factors influencing young peoples' perceptions of personal safety on public transport. Journal of Public Transportation, I6(I), I-I9.

Friberg, T., Brusman, M., Nilsson, M. 2004. Persontransporternas "vita fläckar". Om arbetspendling med kollektivtrafik ur ett jämställdhetsperspektiv. Linköping, Centrum för kommunstrategiska studier.

Gardner, N., Cui, J., Coiacetto, E. 2017. Harassment on public transport and its impacts on women's travel behaviour. Australian Planner, 54(I), 8-15.

Jiron, P. 2009. Mobility on the move. Examining urban daily mobility practices in Santiago de Chile. (Avh.) London School of Economics and Political Science.

Johansson, K., Laflamme, L., Eliasson, M. 2012. Adolescents' perceived safety and security in public space - A Swedish focus group study with a gender perspective. Young 20(I), 69-88. 


\section{UNGDOMARS RESANDEVÄRLD}

Jones, L., Davis, A., Eyers, T. 20oo. Young people, transport and risk: comparing access and independent mobility in urban, suburban and rural environments. Health Education Journal, 59, 315-328.

Kesselring, S. 2006. Pioneering mobilities: new patterns of movement and motilitiy in a mobile world. Environment and Planning A, 38(2), 269-279.

Koskela, H., Pain, R. 200o. Revisiting fear and place: Womens fear of attack and the built environment. Geoforum 3I(2), 269-280.

Lieberg, M. 1995. Teenagers and public space. Communication Research, 22(6), 720-744.

Listerborn, C. 2002. Trygg stad. Diskurser om kvinnors rädsla i forskning, policyutveckling och lokal praktik. (Avh.) Göteborg, Chalmers tekniska högskola.

Massey, D. 2005. For space. London, Sage.

McCray, T., Mora, S. 20II. Analyzing the activity spaces of low-income teenagers: How do they perceive the spaces where activities are carried out? Journal of Urban Affairs, $33(5), 5 \mathrm{II}-528$.

Ocejo, R., Tonnelat, S. 20I4. Subway diaries: How people experience and practice riding the train. Ethnography, I5 (4), 493-515.

Regeringskansliet 2018. Nationell planering för transportinfrastrukturen 2018-2029.

Sheller, M., Urry, J. 2006. The new mobilities paradigm. Environment and planning A, 38(2), 207-226.

Skelton, T. 20I3. Young people's urban im/mobilities: Relationality and identity formation. Urban Studies, 50(3), 467-483.

Symes, C. 2007. Coaching and training: An ethnography of student commuting on Sydney's suburban trains. Mobilities, 2(3), 443-461.

Söderström, M., Lifvin, M., Viberg, J. 2019. Nationella trygghetsundersökningen 20I8. Om utsatthet, otrygghet och förtroende. Stockholm, Brottsförebyggande rådet.

Trafikförvaltningen 20I6. Resvanor i Stockholms län 20I5. Stockholm, Trafikförvaltningen Stockholms läns landsting. 
